Canadian Journal of Higher Education Revue canadienne d'enseignement supérieur

Volume 43, No. 2, 2013, pages 42-67

\title{
Interdisciplinary doctoral research supervision: A scoping review
}

\author{
Meredith Vanstone \\ McMaster University \\ Kathy Hibbert \\ Elizabeth Anne Kinsella \\ Pam McKenzie \\ Allan Pitman \\ Lorelei Lingard \\ Western University (Canada)
}

\begin{abstract}
This scoping literature review examines the topic of interdisciplinary doctoral research supervision. Interdisciplinary doctoral research programs are expanding in response to encouragement from funding agencies and enthusiasm from faculty and students. In an acknowledgement that the search for creative and innovative solutions to complex problems is best addressed through interdisciplinary collaborations, research-intensive universities are increasingly encouraging interdisciplinary projects and programs. The expansion of interdisciplinary research to the context of doctoral research may impact several core components of the doctorate: the enactment of the student-supervisor relationship, the process of forming and working with a supervisory committee, and the process and outcomes of doctoral research. In order to ensure that interdisciplinary doctoral supervision occurs in a positive and effective way, it is necessary to understand the distinct needs and challenges of interdisciplinary students and their supervisors, through scholarship about this phenomenon.
\end{abstract}




\section{Résumé}

Cet article retracela rechercheexistante dansle domaine del'interdisciplinarité ainsi que l'encadrement de recherches doctorales. Les programmes interdisciplinaires de recherches doctorales répondent à l'incitation des organismes de financement et à l'enthousiasme des professeurs et des étudiants et, de ce fait, deviennent de plus en plus nombreux. Les universités centrées sur la recherche encouragent la création de projets et de programmes interdisciplinaires, car elles sont convaincues que les solutions innovatrices et créatives aux problèmes complexes se réalisent par le truchement de collaborations interdisciplinaires. La demande croissante de recherche interdisciplinaire crée cependant un effet important sur plusieurs composantes centrales du doctorat : la mise en œuvre de la relation étudiantsuperviseur; le processus de formation et de travail du comité de supervision; et les processus et résultats de la recherche doctorale. Pour que l'encadrement doctoral interdisciplinaire se déroule de façon positive et efficace, il est donc nécessaire de comprendre clairement quels sont les différents besoins et défis des étudiants et de leurs superviseurs, en fonction du savoir déjà existant dans le domaine.

\section{Introduction}

Interdisciplinary graduate supervision is an expanding phenomenon. Funding agencies are prioritizing interdisciplinary work at the doctoral level, as evidenced by programs such as the U.S. National Science Foundation's Integrative Graduate Education Research and Training Program (National Science Foundation, 2011) and the Canadian Institute of Health Research's Strategic Training Initiatives in Health Research (Canadian Institutes of Health Research, 2006). In response to encouragement from funding agencies, enthusiasm from faculty and students (Rhoten, 2004; Rhoten \& Parker, 2004), and an acknowledgement that the search for creative and innovative solutions to complex problems is best addressed through interdisciplinary collaborations, research-intensive universities are increasingly encouraging interdisciplinary projects and programs (Gibney, Copeland, \& Murie, 2009; Pinar, 2004). The expansion of interdisciplinarity to the context of doctoral research may impact the enactment of the student-supervisor relationship as well as the process and outcomes of graduate research. In order to ensure that interdisciplinary graduate supervision occurs in a positive and effective way, it is necessary to understand the distinct needs and challenges of interdisciplinary students and their supervisors, through scholarship about this phenomenon. This literature review examines the emerging body of literature on interdisciplinary doctoral (ID) supervision, using the guiding research question "what is known about interdisciplinary doctoral supervision?".

Although the supervisory relationship is the backbone of most graduate programs, theoretically grounded research about the dynamics of graduate supervision is still an emerging area of research (Deuchar, 2008; Grant, 2003; Grant, 2005; Halse \& Malfroy, 2010; Lee, 2008; McCallin \& Nayar, 2012; Sambrook, Stewart, Roberts, 2008). Empirical research on this topic may be constrained given that this relationship has been considered private and personal and traditionally conducted "behind closed doors" (Green \& Lee, 1995; McWilliam 
\& Palmer, 1995). In addition, students may not be willing to share negative information about their supervisory experience due to concerns regarding anonymity and the need for a continued good relationship throughout their academic careers (Lee \& McKenzie, 2011).

The recent emergence of interdisciplinary graduate education programs has the potential to further complicate the supervisory relationship, given that interdisciplinarity introduces factors such as cross-disciplinary co-supervision (Kiley, 2009), multiple theoretical orientations on supervisory committees (Nisselle \& Duncan, 2008; Taylor, Beasley, \& Ebrary, 2005), and different orientations to the process of doctoral research. Similar to its disciplinary counterpart, Spelt and colleagues argue that "while interdisciplinary higher education is commonly practiced, a surprisingly small body of theory has accumulated" (Spelt, Biemans, Tobi, Luning, \& Mulder, 2009, p. 378). There is little, if any, available theoretical literature concerning the phenomenon of interdisciplinary graduate supervision; the majority of existing literature focuses on instrumental work, including practical tips for engaging in interdisciplinary doctoral research and supervision, as opposed to empirical and theoretical advances.

\section{Methodology}

A scoping approach to literature review is a systematic way of selecting, collecting, and summarizing a wide range of literature and applying an analytical reinterpretation of the data in order to show the breadth and depth of the topic (Levac, Colquhoun, \& O'Brien, 2010). This approach is particularly useful when the topic to be reviewed is complex (Mays, Roberts, \& Popay, 2001). Methodologically, we followed the approach outlined by Arksey and O'Malley (2005) who suggest that scoping reviews can be used to map fields of study where it is difficult to visualize the range and variation of literature, thereby identifying gaps and areas of saturation in existing literature. From this process, it is possible to contextualize the current state of knowledge and understanding (Anderson, Allen, Peckham, \& Goodwin, 2008) and to draw conclusions regarding the overall state of literature in a particular research area. Scoping reviews include literature with varied study designs, including empirical and theoretical sources, but do not aim to assess the quality of the literature reviewed (Arksey \& O'Malley, 2005).

The scoping approach to literature review goes beyond gathering and reporting data. A scoping review involves intellectual creativity in the analytical phase (Davis, Drey, \& Gould, 2009); requiring "'sense-making' across fields of inquiry that are complex and lend themselves to interpretation through many academic and theoretical disciplines" (Anderson et al., 2008, p.6).

\section{Methods}

The guiding question for this review ("what is known about interdisciplinary doctoral supervision?”) was formulated broadly to incorporate a wide range of existing scholarship in this area (Arksey \& O'Malley, 2005). The aim of the review was to retrieve and critically analyze scholarly literature (empirically or theoretically driven), which contributes to knowledge about this phenomenon. This breadth includes scholarly articles that report on interdisciplinary research projects with attention to the perspectives of supervisors and doctoral students who engage in such projects, supervisor and doctoral student relationships and processes for working with each other, and supervisory committees, funding agencies, doctoral student colleagues, and disciplinary structures. 
"Interdisciplinary" was defined broadly for this review, in order to incorporate as many sources as possible, and included alternate search terms such as multi-disciplinary, integrative, and transdisciplinary. While these terms are not synonyms (Klein, 1990; Klein, 2000; Klein, 2005), research in each of these areas speaks to the complexities of interdisciplinary supervision. These terms have been well defined elsewhere (Klein, 1990; Klein, 2000; Klein, 2005; Lattuca, 2003; Pohl et al 2008). Review was specifically interested in doctoral-level research. Doctoral research was chosen as the focus of the review because it was reasoned that the doctoral degree represents the process of "coming-to-be" a scholar (Green \& Lee, 1995); bachelor's, master's, and professional degree students may not be pursuing an academic career, and post-doctoral fellows may have already formed their scholarly identities. The supervisory relationship was the crux of this study, and while there is ample work on interdisciplinary research and interdisciplinary curricula, there is little work with this specific focus.

Literature was searched via (a) education (ERIC, ProQuest Education, CBCA Education) and interdisciplinary research databases (Scholar's Portal, Google Scholar, IBSS), (b) the library catalogues of Western University and McMaster University, (c) hand searching the reference lists of key publications and key journals, and (d) by inquiring amongst the research team's networks for relevant sources. Table 1 shows the search strategy, which reflects an evolving depth of understanding of the topic as the review progressed (Arksey \& O'Malley, 2005). As this is a relatively new phenomenon, the search strategy was not limited by year. The search tasks were completed in September 2011. The title and/ or abstract of each retrieved paper was read to determine whether the source addressed doctoral supervision specifically, in relation to interdisciplinary doctoral research. If no abstract was available, the table of contents or introduction was used to determine relevance. See Table 1 for a list of search terms. When all the terms from the search categories were used together, there were very few sources available; when all the search terms except for one column were used, there was a profusion of irrelevant sources. Reference lists and lists of citing sources were hand searched, and inquiries were made to scholars working in this area for leads on additional relevant or seminal sources.

Table 1. Search Terms (columns combined with "and", rows combined with "or")

\begin{tabular}{lcc}
\hline Type or Work & Type of Degree & Role \\
\hline Interdisciplinary & Doctoral & Supervis* \\
Cross-disciplinary & PhD & Advis* $^{*}$ \\
Multi-disciplinary & Graduate & \\
Trans-disciplinary & Postgraduate & \\
Integrative & & \\
\hline
\end{tabular}

* indicates the use of the boolean operator for truncation, which expands a search term to include all forms of a root word. 
Due to the paucity of literature (Spelt et al., 2009) addressing interdisciplinary doctoral supervision exclusively, a logic of inclusion rather than exclusion was adopted. Sources that addressed the topic of interdisciplinary doctoral supervision tangentially were included if the section that addressed the relevant area was grounded in scholarly literature. For instance, a source that was mainly about doctoral supervision but also addressed interdisciplinary complications would be included if the mention of interdisciplinary complications was related back to existing scholarly literature.

Eighty-nine sources, including journal articles (54), books (17), essays in edited anthologies (7), grey literature (6), conference proceedings (2) and dissertations (3), were reviewed for the final analysis. These sources were grouped as "primarily relevant" (18), that is, mainly focusing on interdisciplinary doctoral supervision, and as "secondarily relevant" (71), that is, mainly focusing on another topic, however addressing interdisciplinary doctoral supervision as a secondary topic of interest. The sources from the "primarily relevant" group are summarized in Table 2. Two additional relevant papers, published after the search was completed, are also included in Table 2 (Lyall \& Meager, 2012; Parchoma \& Keefer, 2012)

The literature in this area was found to be diverse in terms of discipline, study design, approach, and focus. Data were analyzed according to type: empirical, theoretical, program evaluation, instructional, and reflection on personal experience. The main points (relating to interdisciplinary graduate supervision) of each source were identified and summarized. A thematic analysis of the data was undertaken. Significant thematic overlap in the main points of different types of sources were found, and the data was organized thematically to determine areas of saturation and gaps in the literature. This thematic analysis was iterative, involving identification of themes, discussion amongst members of the research group who considered different ways of organizing the themes and clarified points of contention in thematic organization. The suggestions and critical commentary of the group refined the thematic analysis. 


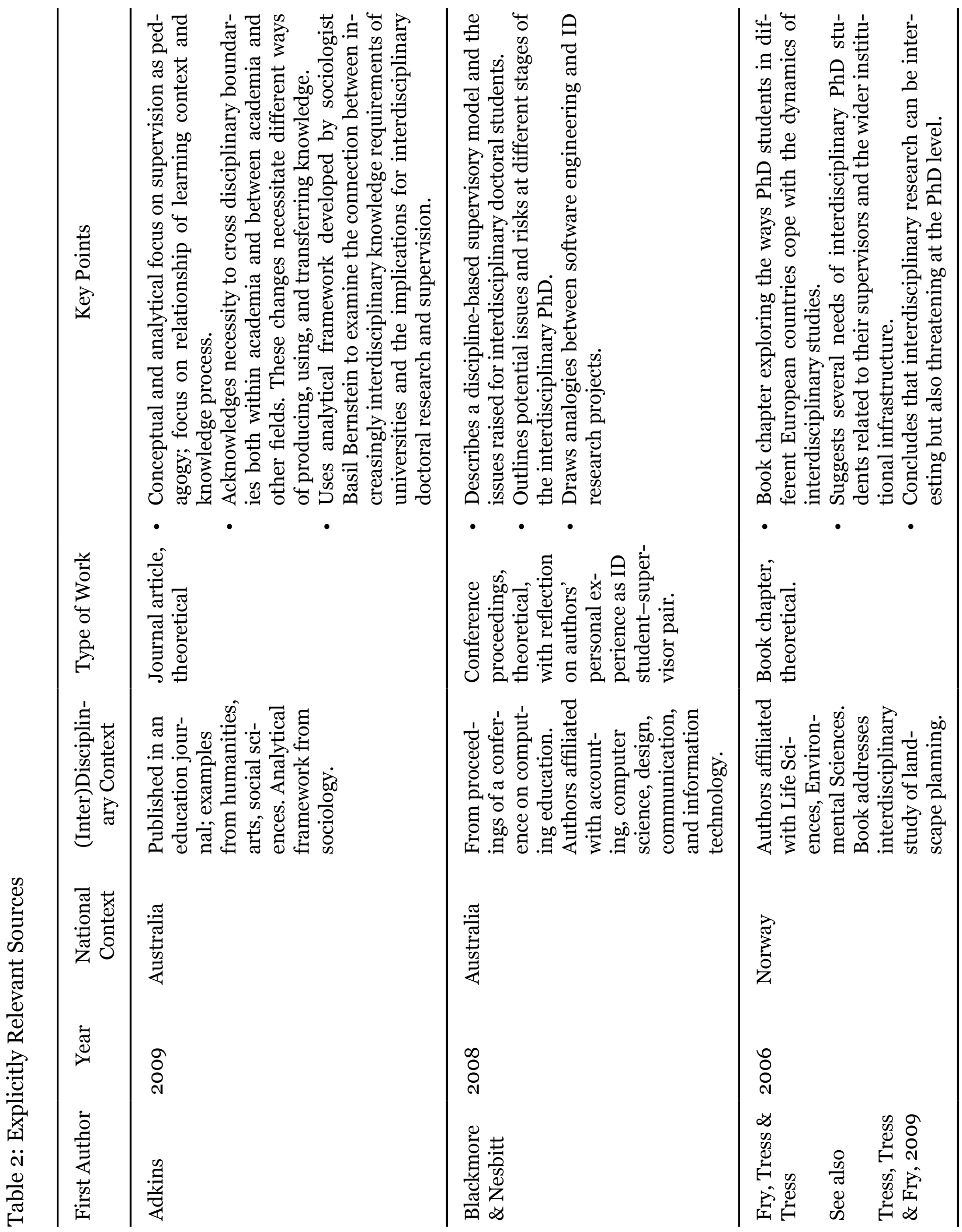




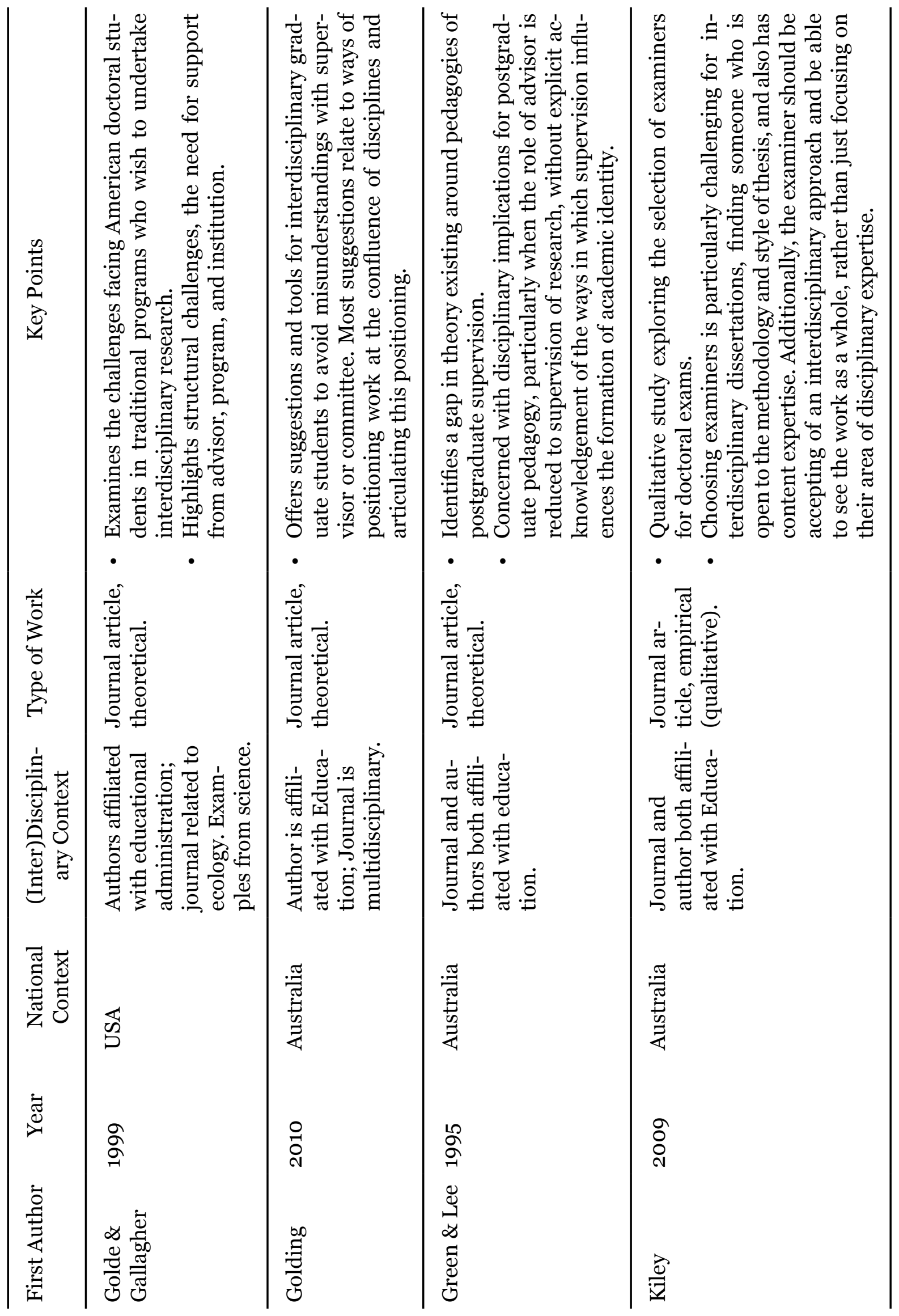




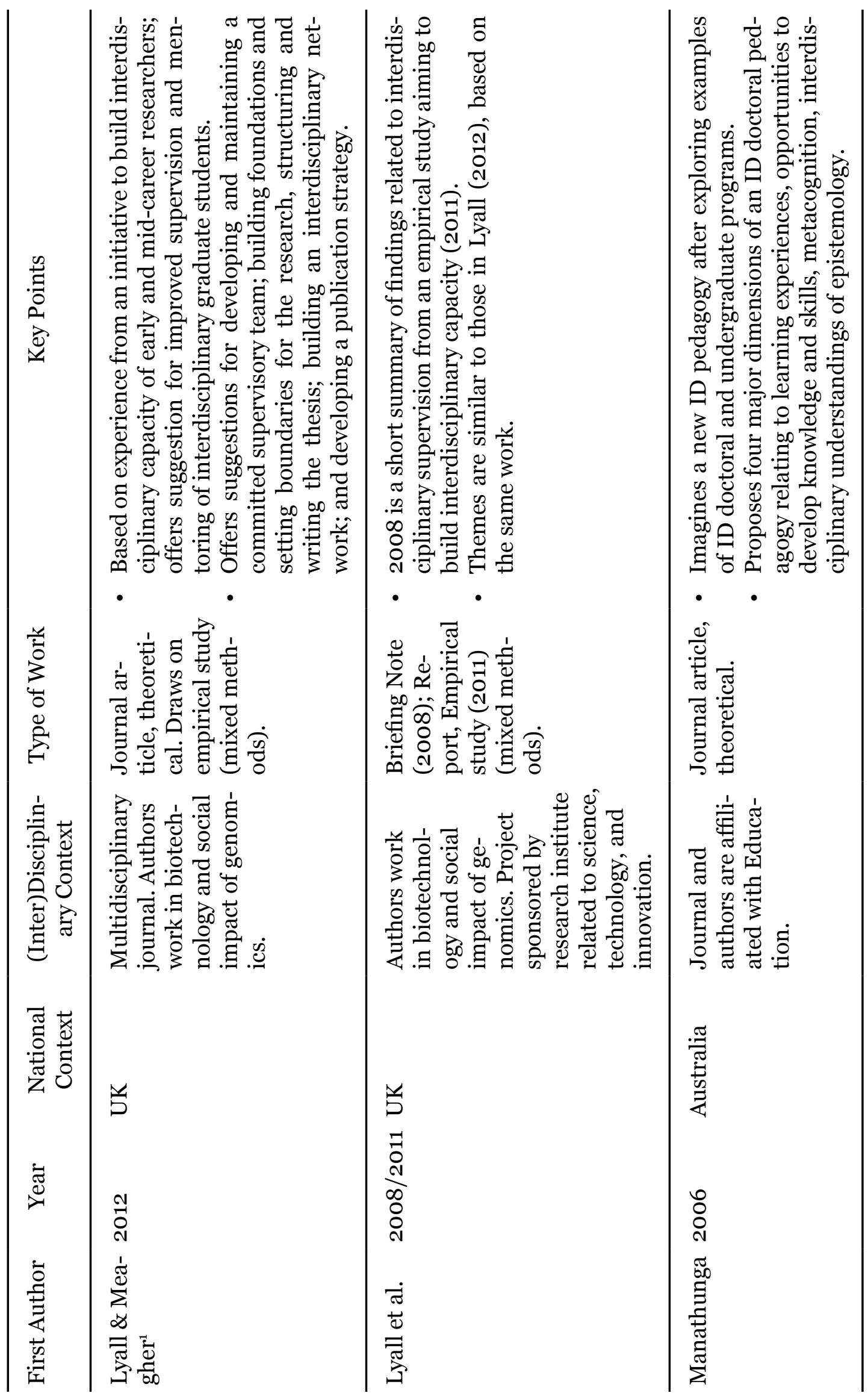




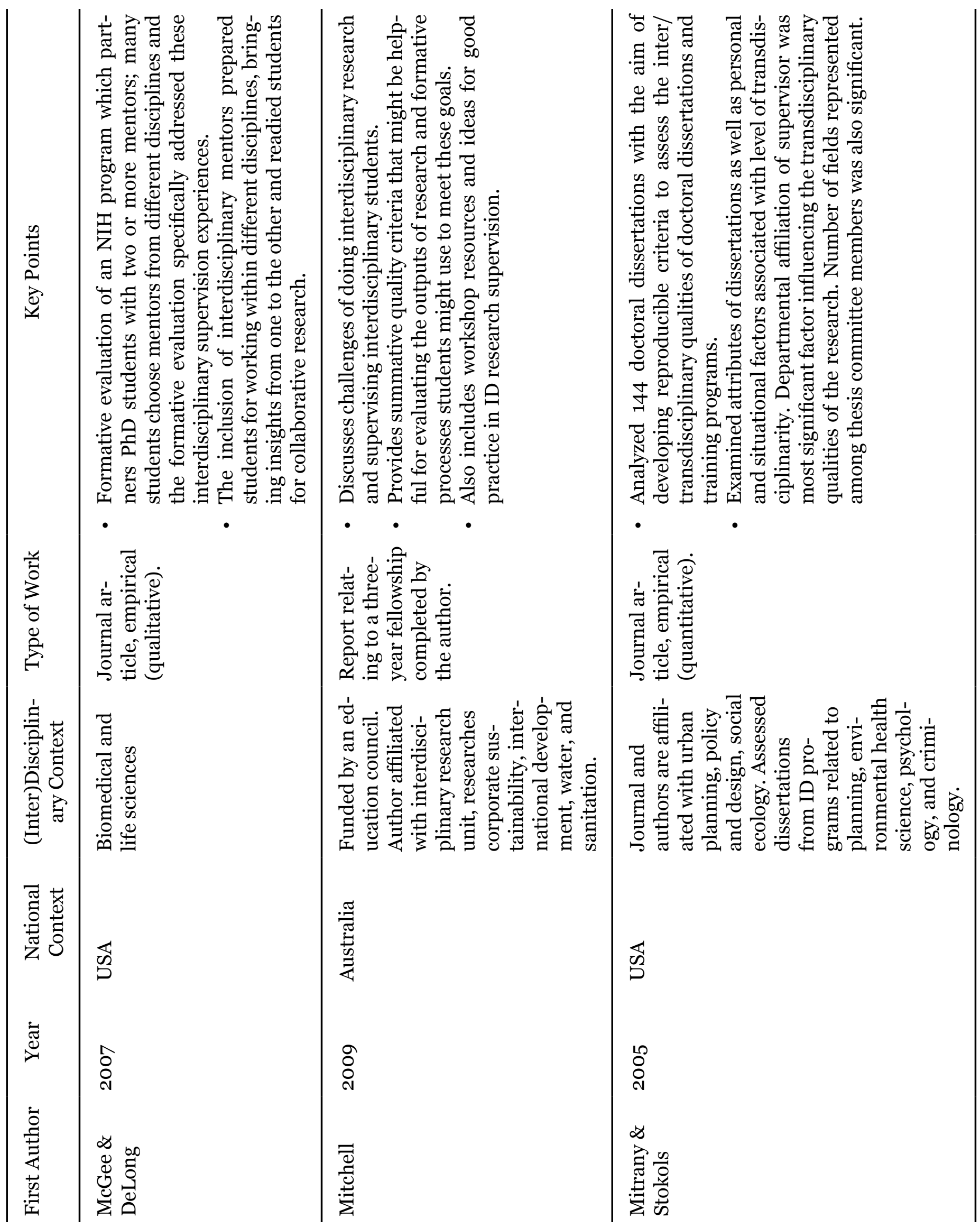




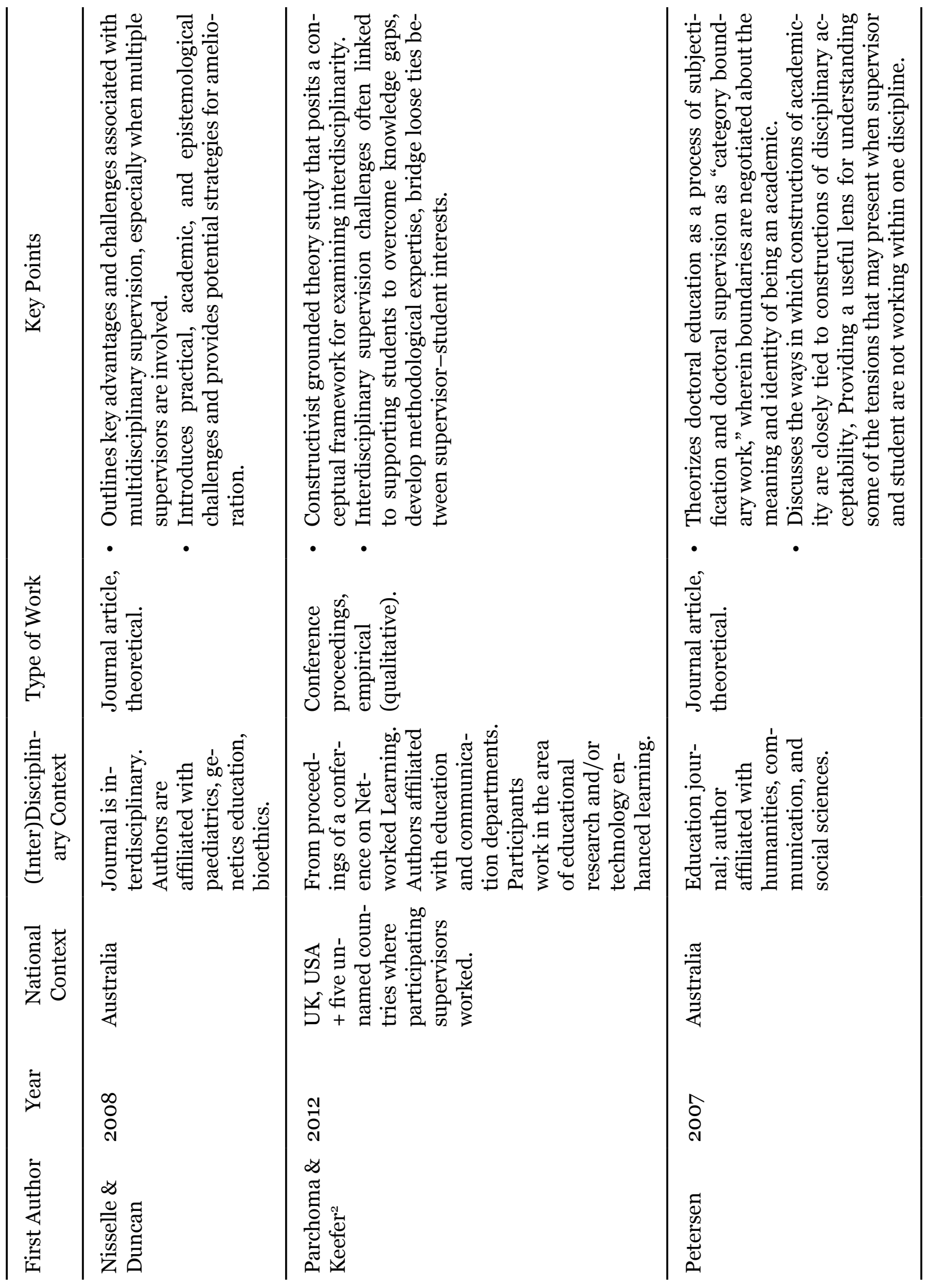




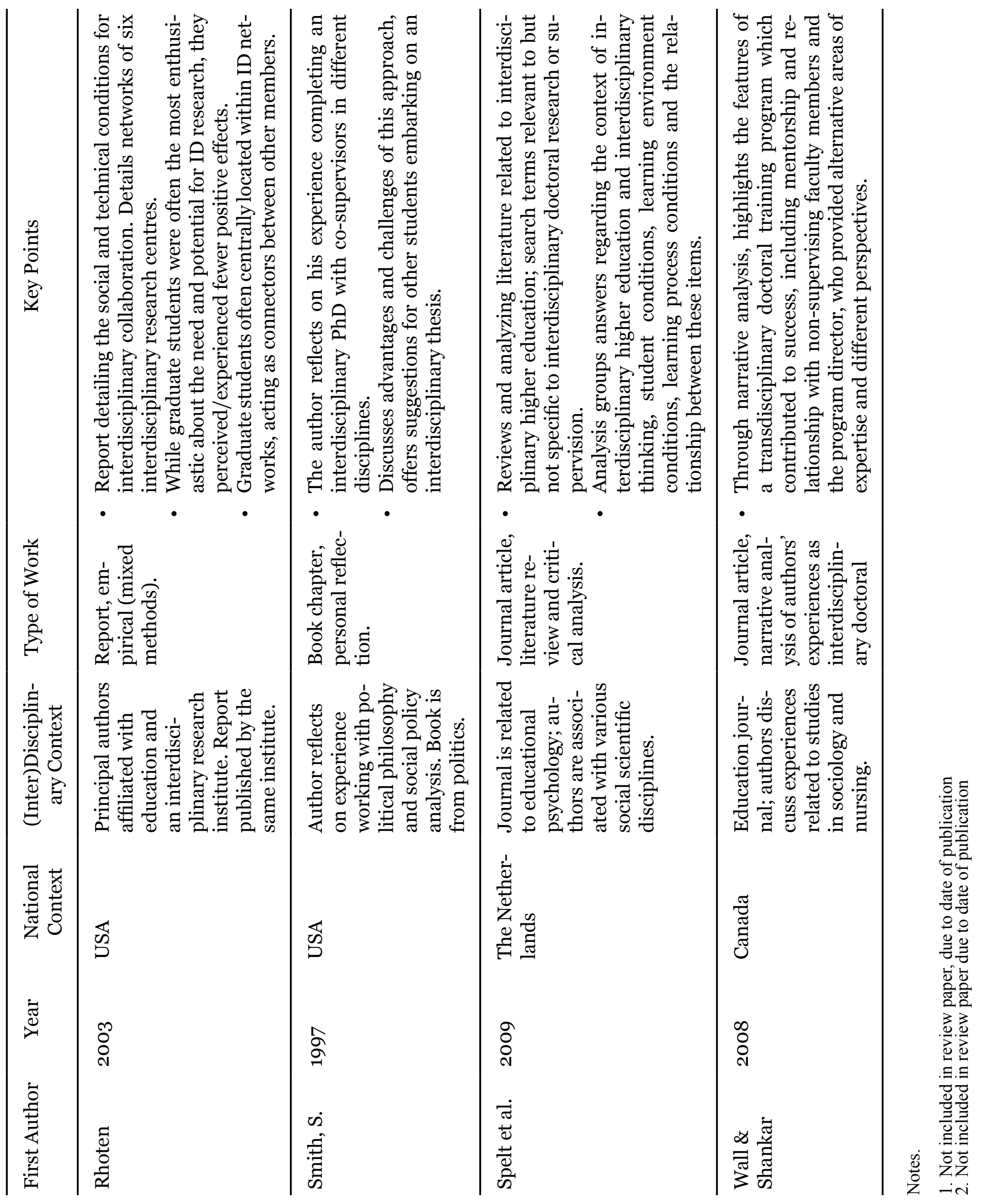




\section{Findings}

There is sparse literature on the specific topic of interdisciplinary doctoral supervision. A recent literature review on the area of teaching and learning in interdisciplinary higher education identified only 13 relevant empirical works on this topic (Spelt et al., 2009). Areas of saturation and gaps in the literature related to interdisciplinary doctoral research supervision will be discussed, and then an integrated analysis of the findings from the literature will be presented.

\section{Mapping Existing Literature: Gaps and Areas of Saturation}

As literature was collected, it was grouped thematically to determine gaps in existing research and areas of saturation. The three identified categories are: (i) descriptions of interdisciplinary doctoral (ID) research, (ii) challenges of ID research, (iii) approaches to successful ID research supervision. Each of the identified categories represent areas of saturation in the current literature and opportunities for future research.

I. Descriptions of interdisciplinary doctoral research. Descriptions of interdisciplinary doctoral (ID) research, defined as definitions of ID research and descriptions of ID programs, is a well-saturated area of research. Within the literature on ID research, there is widespread acceptance of Klein's taxonomy of interdisciplinarity (Klein, 2010; Klein, 1990), with some authors using more nuanced definitions combining the ideas of several scholars, often including Klein. Beyond this approach to defining interdisciplinarity, some authors choose to work with their own definitions, or without defining their particular version of interdisciplinarity. Among those working with their own definitions, there is little consistency or precision in these definitions, perhaps reflecting that despite a growing body of literature, "interdisciplinarity is not a unified and clearly defined phenomenon" (Manathunga, Lant, \& Mellick, 2006, p. 366).

There is a significant amount of literature describing particular interdisciplinary doctoral programs (Copenheaver, Nelson, \& Goldbeck, 2009; Coryn, Stufflebeam, Davidson, \& Scriven, 2010; da Sousa Correa, Chornik, \& Samuels, 2009; McGee \& DeLong, 2007; Mcvicar et al., 2006; Rhoten, 2003; Rhoten \& Parker, 2004; Skarakis-Doyle \& Doyle, 2008; Stufflebeam, 2001; Sugimoto, 2010). This literature is focused on articulating current practices with varying degrees of description, reflection, and use of empirical data. The phenomenon of supervision in these programs is mostly a tangential topic in the description of current practices. With the exception of Rhoten and colleagues' study of five interdisciplinary research programs (Rhoten, 2003; Rhoten \& Parker, 2004; Rhoten, 2004) and Enders' (2005) examination of different modes of doctoral research training (Enders, 2005), this literature concerns single-site studies with various levels of empirical data. Empirical research in this area includes formative evaluation (McGee \& DeLong, 2007) surveys, interviews (Sugimoto, 2010), bibliometric approaches (Sugimoto, 2010), and academic genealogical analysis (Copenheaver et al., 2009). Generally the literature in this area is descriptive, offering a historical account of how the program came to be, the disciplines involved, a characterization of the areas of expertise of the faculty members and students, and a justification for why interdisciplinary work is necessary in this topic area. These articles rarely comment on how their specific programs relate to other interdisciplinary programs or interdisciplinary scholarship on a broader scale; there is little theoretical development in this body of literature. 
There is a gap in research concerning multi-site comparisons of interdisciplinary doctoral programs. Rhoten and colleagues (Rhoten, 2003; Rhoten \& Parker, 2004) have undertaken a multisite comparison of interdisciplinary research centres, however they do not focus on graduate supervision. There is also little literature that examines institutional barriers and facilitators of ID supervision. Sá's work investigating institutional barriers and facilitators to interdisciplinary research conducted by faculty suggests that this may be a rich area of study in the context of doctoral research and supervision (Sá, 2006; Sá, 2008a; Sá, 2008b). There have been suggestions of institutional constraints that may challenge interdisciplinary supervisors and students who work in traditional research programs (Golde \& Gallagher, 1999; Mitrany \& Stokols, 2005) and an examination of the institutional conditions that create a learning environment that encourages interdisciplinary doctoral work (Spelt et al., 2009); however empirical comparative work in this area is sparse. In addition to a lack of empirical work in this area, there is a paucity of theoretical work, a gap that will be further discussed as an opportunity for future scholarship.

II. Challenges of ID research. By far the most saturated area of literature is reflective papers that combine reflection on personal experience of ID research with a survey of selected literature. The literature in this category tends to focus on challenges of ID research, from the perspective of the author (Golding, 2010; Hagoel \& Kalekin-Fishman, 2002; Martin, 2011; Nisselle \& Duncan, 2008; Robinson, 1997; Smith, 2001; Smith, 1997; Wall \& Shankar, 2008). There is little work on the potential strengths of ID research, although most authors mention why they were drawn to work in an interdisciplinary way, commonly for reasons of interest in the topic or a desire to produce information that was applicable to real world problems.

In addition to the sources related to personal experience as an interdisciplinary doctoral student or supervisor, there are a few sources that address the challenges of ID research from theoretical or empirical perspectives rather than descriptive or experiential perspectives. Such work is well grounded in existing literature on supervisory pedagogy and interdisciplinary research (Fry, Tress \& Tress, 2006; Pole, 1998; Sampson \& Comer, 2010; Tress, Tress, \& Fry, 2009). Also addressing the challenges of ID research are a number of instructional books that mention interdisciplinary doctorates in a passing way, on the topics of supervising doctoral students (Bartlett \& Mercer, 2001; Delamont, Atkinson, \& Parry, 2004; Eley \& Jennings 2007; Gordon \& Habley, 2000; Nightingale \& Higher Education Research and Development Society of Australasia, 2005; Taylor et al., 2005; Wisker, 2005) or completing a doctorate (Bartlett \& Mercer, 2001; Burnham, 1997; Finn, 2005; Phillips \& Pugh, 2005; Semenza, 2005).

III. Approaches to successful ID research supervision. Category (iii) describes potential tools or approaches for successful supervision of ID research. It is the least developed area of literature, with most work falling into two categories: (a) theoretical considerations for interdisciplinary pedagogies for doctoral supervision and (b) work regarding the development and use of evaluation tools for ID research, both empirical and theoretical.

Several authors agree that ID research requires a different pedagogy of supervision than single disciplinary doctoral research (Bauer, 1990; Delamont et al., 2004; Green \& Lee, 1995; Hodge, 1995; Manathunga et al., 2006; Mitrany \& Stokols, 2005; Mitchell, 2009a; Mitchell \& Willetts, 2009). Petersen (2007) has developed an analytical tool based on the concept of category boundary work to examine the ways in which the su- 
pervisory relationship shapes graduate students as academics. This conceptualization is explicitly context sensitive and provides a useful lens with which to consider the unique challenges that may be encountered by those in ID supervisory relationships, as well as the differences between "becoming" an interdisciplinary scholar versus a disciplinary scholar (Petersen, 2007). Some pedagogical literature remains a theoretical or philosophical reflection on the phenomena (Bauer, 1990; Green \& Lee, 1995; Hodge, 1995), while others move beyond the broader scholarship on supervision pedagogy to generate pedagogical elements that may be specifically relevant to interdisciplinary supervision. Common proposed pedagogical elements include epistemological and methodological coherence, flexibility when working with a wide variety of literature and methodologies. a self-reflexive disposition, a reflexive orientation towards different bodies of knowledge, emphasis on contribution, and communication to multiple types of audiences (Green \& Lee, 1995; Manathunga et al., 2006; Mitchell, 2009a; Mitchell \& Willetts, 2009; Mitrany \& Stokols, 2005; Smith, 2001)

The literature on ID evaluation is divided into two different types: theoretical and empirical. The theoretical literature on evaluation of ID research is congruent with the pedagogical literature, sometimes co-existing in a single text (e.g. Adkins, 2009; Boix-Mansilla \& Duraising, 2007; Mitchell, 2009a; Mitchell \& Willetts, 2009). Common themes in theoretical approaches to evaluation of interdisciplinary literature include an emphasis on responsive and reflexive goals; broad preparation and mastery of process; evolution of epistemology, methodology, and methods so as to achieve coherency and alignment; critical reflection and reflexivity; effective communication to diverse groups; critical and pluralistic engagement with the literature (Hodge, 1995; Mitchell, 2009a; Wickson, Carew, \& Russell, 2006)

Empirical research concerning evaluation of interdisciplinary student work is a small but growing body of literature. Harvard's Interdisciplinary Studies Project has contributed insights of faculty who participate in evaluation of interdisciplinary work (Boix Mansilla, 2006; Boix-Mansilla \& Duraising, 2007; Rhoten, Boix-Mansilla, Chun, \& Klein, 2006) and the project reports on the results of an exercise in interdisciplinary collaborative evaluation of student work (Boix-Mansilla, 2005). Others developed quality criteria by examining student work such as successful graduate scholarship applications and dissertations (Borrego \& Newswander, 2010; Mitrany \& Stokols, 2005).

\section{Thematic Analysis}

The thematic analysis is organized into two parts: an analysis of the themes in the existing literature (Existing Knowledge about Interdisciplinary Doctoral Supervision) and a secondary analysis (Gaps in Knowledge) that asks what the next steps are, where opportunities exist for more research, and what needs to be explored further.

\section{Existing Knowledge about Interdisciplinary Doctoral Supervision}

There are several key themes frequently occurring in the literature that we have conceptualized as challenges (1a) and suggestions for overcoming challenges (1b).

1a. Challenges of Intellectual and Physical Diffusion. Interdisciplinary work necessitates a move outside of the disciplinary-departmental format that structures most 
doctoral research. Without the traditional structure of disciplinary departments or programs, interdisciplinary students may find that the physical and intellectual resources they wish to access are not necessarily available in a single format, location, or cohesive package. In this section of the paper, the challenges of intellectual and physical diffusion, the possible barriers students may encounter as they pursue interdisciplinary research are identified from the literature.

The phrase "intellectual diffusion" refers to ideas that may not commonly occur together and may have to be sought out, reconciled, explained, or justified as a package. This may include institutional factors such as different departmental or disciplinary expectations for the elements of the Ph.D., for instance the format and content of a research proposal or comprehensive exams (Blackmore \& Nesbitt, 2008). An interdisciplinary student may need to contend with different visions of the purpose of the Ph.D. Do the different disciplines involved consider the $\mathrm{PhD}$ a vocational goal or a vehicle for student development (Nisselle \& Duncan, 2008)? As in single disciplinary doctoral degrees, students may grapple with different supervisory conceptions of whether the content or the act of learning is of primary importance (Franke \& Arvidsson, 2011), or encounter different ideas of what a $\mathrm{PhD}$ is and how it is done, both of which may also affect relationships with supervisors (Pole, 1998). The student and supervisor or co-supervisors may have distinct ideas about the supervisory role. Does the supervisor act as a project leader or supervisor (Franke \& Arvidsson, 2011)? Is supervision an administrative or pedagogical task (B. Smith, 2001)? This misunderstanding of roles may be complicated by the propensity for interdisciplinary students to have co-supervisors (Kiley, 2009). Inconsistent views of the nature of supervision may affect the academic success and identity of the student (Smith, 2001). Green and Lee contend that "supervision is not just coming to know, it is also coming to be" (Green \& Lee, 1995), a formation of the academic self (Manathunga, 2007; Petersen, 2007). Peterson (2007) suggests that through the supervisory relationship, individuals "come to embody insidious and tacit knowledges re: how to express recognition of competence, how to express our recognition that what someone does or says falls outside the domain of the appropriately academic," (Smith, B., 2001, p.30) and that we learn this through multiple social and discursive sites. Reconciling conflicting messages may be challenging, as models of supervision are a product of "deeply entrenched cultural norms that we may not even be aware of" (Smith, B., 2001, p.30).

Interdisciplinary supervisory committees bring intellectual diversity although single disciplinary students may also face these issues on their supervisory committees. Taylor suggests it is important for all members of a supervisory committee to have a common framework for understanding basic matters of research such as epistemology, relation of theory to practice, and ways of locating problems and finding solutions (Taylor et al., 2005). That is not to say that each member of the committee should agree or share the same theoretical lens, but that it is important for all members to have a way to discuss these issues in an explicit way and to negotiate how best to support the student. A few authors (Nisselle \& Duncan, 2008; Taylor et al., 2005) suggest that without this discussion, there is a possibility for "disciplinary chauvinism" within the committee, undermining the concept of interdisciplinary work.

Beyond the supervisory relationship, interdisciplinary students may be challenged when working outside of disciplinary or departmental lines by a lack of a peer group who 
can evaluate interdisciplinary research for funding (Hagoel \& Kalekin-Fishman, 2002) or peer review publications (Wickson et al., 2006). Interdisciplinary students often struggle to find evaluators or examiners who can see the project from multiple angles rather than assessing it from a single disciplinary perspective (Kiley, 2009), which may be disadvantageous when work considered stylistically appropriate in one discipline may not be appropriate in another (Blackmore \& Nesbitt, 2008). Interdisciplinary research initiatives may be educating strong scholars who struggle to fit into disciplinary frameworks for success.

Academic work is often rewarded or productivity assessed through disciplinary structures such as disciplinary publications, departmental promotions (Greybill \& Shadas, 2010; Pfirman \& Martin, 2010), or disciplinary funding mechanisms (Golde \& Gallagher, 1999). In both external and internal assessment situations, disciplinary groups are the primary locus of control over doctoral education (Golde \& Gallagher, 1999). Some authors suggest it is essential that ID students learn to work in a style acceptable to both and in a way that constitutes a contribution to both bodies of knowledge (Golde \& Gallagher, 1999; Nisselle \& Duncan, 2008). In this body of literature, the onus is on students to learn and work in ways that fit traditional academic structures with little emphasis on changing the way academic structures work with interdisciplinary scholars and no calls for interdisciplinary institutions or journals to accommodate the burgeoning amount of interdisciplinary work were found.

The challenges of intellectual diffusion may be exacerbated by physical diffusion. It may be difficult for students to find an advisor who is interested and capable of supervising an interdisciplinary project on the topic of interest at their institution (Golde \& Gallagher, 1999). Depending on institutional arrangements, faculty members may not be recognized or rewarded for supervising students outside their home department; institutional structural arrangements can be instrumental in encouraging or discouraging interdisciplinary collaboration (Sá, 2006; Sá, 2008a; Sá, 2008b). In order to obtain the necessary supervisory expertise, interdisciplinary students may be more likely to have co-supervisors (Kiley, 2009), introducing a new set of advantages and complications. Co-supervisors located in different disciplines may be physically separate in the university and may not have worked together before, necessitating the need for the student to develop independence and communication skills (McGee \& DeLong, 2007). Physical diffusion also raises issues of office space for interdisciplinary students or accommodation into an existing group of supervised students (Golde \& Gallagher, 1999). Co-supervised doctoral students may also struggle with a diffusion of academic responsibility, where no single faculty member is responsible for the academic progress of the student (Phillips \& Pugh, 2005).

1b. Ameliorating Challenges. One of the challenges of ID research is the establishment of expectations for achievement. Supervisors, examiners, and peer reviewers from different disciplines may have different ideas about quality criteria (Boix-Mansilla, 2005), about the expectations, purpose, and nature of interdisciplinary work (Boix Mansilla, 2006), and about the requirements of an interdisciplinary doctorate (Taylor et al., 2005). This may also be true of disciplinary doctoral students, but different perspectives are likely to be amplified in interdisciplinary situations (Golde \& Walker, 2006).

We may currently be working at a time of epistemological evolution in academia in terms of evolving standards to accommodate ID work, evidenced by a shift in the humani- 
ties to standards of reflexivity, situation/standpoint, means of production and re-presentation (Hodge, 1995), and a shift in the sciences towards research carried out in the context of application rather than in the context of a particular academic discipline (Enders, 2005). This shift is reflected in the quality criteria proposed by a number of authors (see Manathunga et al., 2006; Mitchell, 2009b; Mitchell \& Willetts, 2009; Mitrany \& Stokols, 2005; Wickson et al., 2006) who share a common emphasis on assessing ID work based on contribution to different knowledge domains, breadth versus depth considerations, reflexivity towards work, coherent theoretical perspectives, and effective communication (Manathunga et al., 2006; Mitchell, 2009a; Mitchell \& Willetts, 2009; Wickson et al., 2006).

These types of quality criteria require a coherence between epistemological assumptions and methodologies, including understanding and communicating the limitations and values of chosen approaches (Mitrany \& Stokols, 2005). There is also an emphasis on the thoughtful pairing of epistemologies and methodologies. Disciplinary knowledge cannot be isolated from its epistemology, methods, theories, and history (Bauer, 1990), but interdisciplinary students can use different bodies of knowledge to critically reflect upon other forms of knowledge in a transformative way, deconstructing and rebuilding a new body of knowledge (Adkins, 2009; Wickson et al., 2006). This type of deconstructive/ generative work is an example of how interdisciplinary research may require more time and effort from a student, leaving that student potentially feeling overwhelmed (Golde \& Gallagher, 1999). Interdisciplinary research may also require more investment from students in developing expertise in more than one area (Blackmore \& Nesbitt, 2008; Golde \& Gallagher, 1999; Mitrany \& Stokols, 2005), working with supervisors who have different viewpoints and ameliorating their suggestions (Nisselle \& Duncan, 2008), and working with a supervisor who does not share epistemological or paradigmatic foundations with the student (Robinson, 1997). However, these challenges may also make interdisciplinary doctoral work more theoretically rigourous.

Due to the requirement for more work than single disciplinary research (Tress et al., 2009), students embarking on interdisciplinary work should have a commitment to working in this way, a belief that the combination of two disciplines can produce better explanations or richer solutions than a single discipline (Smith, S., 1997), an interest in the topic, dedication to practical relevance, a desire for intellectual stimulation, or a wish to do innovative work ( Fry et al, 2006; Tress et al., 2009).

\section{Gaps in Knowledge}

Much of the literature is focused on potential challenges for ID students. Challenges are discussed directly or through suggestions for amelioration; however there is scant literature that focuses on the positive aspects of ID research. One exception is Wall and Shankar (2008), who are explicit about their intent to focus on the positive potential of mentorship for ID researchers. Many authors address the topic with an introductory paragraph about the "importance" of interdisciplinary research or mention enthusiasm for this type of work from funding agencies or industry, yet there is little empirical work about the benefits or advantages to interdisciplinary students. This gap is an important one to explore in order to formulate best practice guidelines for supervision and to determine advantages or disadvantages faced by ID students when competing for jobs and funding in an institutional world that rewards disciplinarity (Rhoten \& Parker, 2004; Rhoten, 2004). We 
assume here, supported by previous research, that interdisciplinary researchers face many similar issues, regardless of what disciplines are being combined (Rhoten et al, 2006; Lyall \& Meager, 2012) and it may be feasible to suggest broad guidelines for interdisciplinary supervision that would be helpful across different areas of research.

There is little empirical work on the advantages and disadvantages of interdisciplinary work during the doctorate, and that which does exist concerns evaluation standards, or is a single-site program evaluation or analysis of theses produced by a particular program. There is ample room for empirical research on ID work, particularly around processes and outcomes for these students. As previously mentioned, the area of definitions of interdisciplinarity is well saturated, with widespread commitment to the taxonomy of interdisciplinarity developed by Klein (Klein, 2010; Klein, 1990; Klein, 2000; Klein, 2006). Yet, it is still unknown whether these definitions have been adopted in practice. Do students and supervisors working on interdisciplinary projects adopt a specific definition of interdisciplinarity or work with individualized, idiosyncratic definitions of this approach?

The existing scholarship on ID research is primarily based on previous scholarship about single disciplinary doctoral research. There are two potential implications to this. First, it raises questions about the difference between single disciplinary and interdisciplinary doctoral research. Without empirical and theoretical work in this area it is impossible to draw any conclusions about the potential similarities and differences between single disciplinary and interdisciplinary doctoral supervision. Some of the literature on single disciplinary doctoral research appears consistent with the experiences of those working with ID students; other literature seems dissonant. While there are, no doubt, commonalities between the two approaches to research, the question arises - are the differences truly different? Or are the differences simply an amplification of challenges that single disciplinary doctoral students also face, such as the challenge of co-supervisors with different areas of expertise or the need to amalgamate different faculty member's expectations of quality? More research is needed to understand the relationship of these two approaches to doctoral research. Second, if we assume there are differences between single disciplinary and ID researchers, what are the implications for conducting research about the phenomenon of interdisciplinary research within the hegemony of the disciplinary frame in academia? If ID research is considered within the frame and structure of single disciplinary doctoral research, what opportunities are missing for further innovation and insight? Is there room for consideration of ID research in its own right, outside of the boundaries and expectations created by traditional disciplinary work? Researchers in this area might ask themselves if they are approaching their research from a disciplinary perspective, expecting the outcome to fit back into a disciplinary frame. They may wish to ask what kind of scholars are we creating through ID study? Where will they fit in the academic world? What kind of opportunities are there for interdisciplinary scholars and how can doctoral education best prepare them to capitalize on these opportunities? When considering the literature on ID supervision in this light, it is clear there is a need for creative, generative research that will provide theory and evidence to encourage excellence in ID research. There is opportunity for this body of research to move beyond existing research that has mapped the surface of the phenomenon to explore the cultural, structural, institutional, and epistemological depths of possibility. 


\section{Conclusion}

There is little literature specific to ID research although it is a topic commonly addressed in a tangential way by scholars concerned with doctoral research in general or interdisciplinary research in general. The literature that exists in this area is concentrated in accounts of personal experience, descriptions and evaluations of particular doctoral programs, and theoretical work on supervision pedagogy. Many authors claim that interdisciplinary work is becoming more prevalent at the doctoral level, but that has yet to be established on a national or international level. If true, as suggested by single-site studies and anecdotal evidence, the body of knowledge in this area would benefit from more empirical and theoretical exploration of barriers to and facilitators of ID research, exploration of outcomes for students who study in this way, and an examination of processes that lead to success.

\section{References}

Adkins, B. (2009). PhD pedagogy and the changing knowledge landscapes of universities. Higher Education Research \& Development, 28(2), 165-77.

Anderson, S., Allen, P., Peckham, S., \& Goodwin, N. (2008). Asking the right questions: Scoping studies in the commissioning of research on the organisation and delivery of health services. Health Research Policy and Systems, 6(1), 7.

Arksey, H., \& O'Malley, L. (2005). Scoping studies: Towards a methodological framework. International Journal of Social Research Methodology, 8(1), 19-32.

Bartlett, A., \& Mercer, G. (2001). Postgraduate research supervision : Transforming (r)elations. New York: Lang.

Bauer, H. H. (1990). Barriers against interdisciplinarity: Implications for studies of science, technology, and society (STS). Science, Technology \& Human Values, 15(1), 105119.

Blackmore, K., \& Nesbitt, K. (2008). Identifying risks for cross-disciplinary higher degree research students. Proceedings of the Tenth Conference on Australasian Computing Education, 78, 43-52.

Boix-Mansilla, V. (2005). Productive shifts: Faculty growth through collaborative assessment of student interdisciplinary work. Journal of Learning Communities Research, 3(3), 21-26.

Boix-Mansilla, V. (2006). Assessing expert interdisciplinary work at the frontier: An empirical exploration. Research Evaluation, 15, 17-29.

Boix-Mansilla, V., \& Duraising, E. D. (2007). Targeted assessment of students' interdisciplinary work: An empirically grounded framework proposed. The Journal of Higher Education, 78(2), 215-237.

Borrego, M., \& Newswander, L. (2010). Definitions of interdisciplinary research: Toward graduate-level interdisciplinary learning outcomes. Review of Higher Education, 34(1), 61. 
Burnham, P. (1997). Surviving the research process in politics. London; Washington DC: Pinter.

Canadian Institutes of Health Research. (2006). Research profile - training tomorrow's health researchers today: CIHR's interdisciplinary training programs. Retrieved from http://www.cihr-irsc.gc.ca/e/30227.html

Copenheaver, C. A., Nelson, K. L., \& Goldbeck, K. (2009). The academic roots of forestry programs: A case study from Virginia Tech. Journal of Natural Resources and Life Sciences Education, 38, 99-105.

Coryn, C. L. S., Stufflebeam, D. L., Davidson, E. J., \& Scriven, M. (2010). The interdisciplinary Ph.D. in evaluation: Reflections on its development and first seven years. Journal of Multidisciplinary Evaluation, 6(13), 118-129.

da Sousa Correa, D., Chornik, L., \& Samuels, R. (2009). Literature and music: Interdisciplinary research and teaching at the Open University. Working with English: Medieval and Modern Language, Literature and Drama, 50-61.

Davis, K., Drey, N., \& Gould, D. (2009). What are scoping studies? A review of the nursing literature. International Journal of Nursing Studies, 46(10), 1386-1400.

Delamont, S., Atkinson, P., \& Parry, O. (2004). Supervising the doctorate: A guide to success (2nd ed.). London: Society for Research into Higher Education.

Deuchar, R. (2008). Facilitator, director or critical friend? Contradiction and congruence in doctoral supervision styles. Teaching in Higher Education, 13(4), 489500 .

Eley, A. \& Jennings, R. (2007). Effective postgraduate supervision. Maidenhead, UK: McGraw-Hill International.

Enders, J. (2005). Border crossings: Research training, knowledge dissemination and the transformation of academic work. Higher Education, 49 (1-2), 119-113.

Finn, J. A. (2005). Getting a PhD. New York: Routledge.

Franke, A., \& Arvidsson, B. (2011). Research supervisors' different ways of experiencing supervision of doctoral students. Studies in Higher Education, 36(1), 7-19.

Fry, G., Tress, B., \& Tress, G. (2006). PhD students and integrative research. In B. Tress, G. Tress, G. Fry, \& P. Opdam (Eds.). From Landscape Research to Landscape Planning: Aspects of Integration, Education and Application (pp193-205). Netherlands: Springer.

Gibney, J., Copeland, S., \& Murie, A. (2009). Toward a 'New' strategic leadership of place for the knowledge-based economy. Leadership, 5(1), 5-23.

Golde, C. M., \& Gallagher, H. A. (1999). The challenges of conducting interdisciplinary research in traditional doctoral programs. Ecosystems, 2(4), 281-285.

Golde, C. M., \& Walker, G. (2006). Envisioning the future of doctoral education: Preparing stewards of the discipline. Stanford: Carnegie Foundation for the Advancement of Teaching. 
Golding, C. (2010). Positioning interdisciplinary graduate research (or how to avoid painful misunderstandings with your supervisors and examiners). Traffic (Parkville), 12(1), 17-37.

Gordon, V. N., \& Habley, W. R. (2000). Academic advising: A comprehensive handbook. San Francisco: Jossey-Bass.

Grant, B. (2003). Mapping the pleasures and risks of supervision. Discourse, 24(2), 175-190.

Grant, B. M. (2005). Fighting for space in supervision: Fantasies, fairytales, fictions and fallacies. International Journal of Qualitative Studies in Education, 18(3), 337-354.

Green, B., \& Lee, A. (1995). Theorising postgraduate pedagogy. Australian Universities' Review, 2(1), 41.

Greybill, L., \& Shadas, V. (2010). Doctoral student and early career academic perspectives. In R. Frodeman, J. Thompson Klein \& C. Mitcham (Eds.), The Oxford Handbook of Interdisciplinarity (pp. 405). Oxford; New York: Oxford University Press.

Hagoel, L., \& Kalekin-Fishman, D. (2002). Crossing borders: Toward a transdisciplinary scientific identity. Studies in Higher Education, 27(3), 297-308.

Halse, C., \& Malfroy, J. (2010). Re-theorizing doctoral supervision as professional work. Studies in Higher Education, 35(1), 79-92.

Hodge, B. (1995). Monstrous knowledge: Doing PhDs in the new humanities. Australian Universities' Review, 2(1), 35.

Kiley, M. (2009). "You don't want a smart alec": Selecting examiners to assess doctoral dissertations. Studies in Higher Education, 34(8), 889-308.

Klein, J. (1990). Interdisciplinarity: History, Theory, and Practice. Detroit: Wayne State University.

Klein, J. (2000). Conceptual vocabulary of interdisciplinary science. Practicing Interdisciplinarity (pp. 3-24). Toronto: University of Toronto Press.

Klein, J. (2005). Integrative learning and interdisciplinary studies. Peer Review, 8-10.

Klein, J. (2006). A platform for a shared discourse of interdisciplinary education. English Faculty Research Publications. Paper 3. Retreived from http://digitalcommons. wayne.edu/englishfrp/3.

Klein, J. (2010). A taxonomy of interdisciplinarity. In R. Frodeman, J. Thompson Klein, \& C. Mitcham (Eds.), The Oxford Handbook of Interdisciplinarity (pp. 15). Oxford; New York: Oxford University Press.

Lattuca, L. (2003). Creating interdisciplinarity: Grounded definitions from college and university faculty. Histoy of Intellectual Culture, 3(1), 1-20.

Lee, A. (2008). How are doctoral students supervised? Concepts of doctoral research supervision. Studies in Higher Education, 33(3), 267-281.

Lee, A., \& McKenzie, J. (2011). Evaluating doctoral supervision: Tensions in eliciting students' perspectives . Innovations in Education \& Teaching International, 48(1) 69-78. 
Levac, D., Colquhoun, H., \& O’Brien, K. (2010). Scoping studies: Advancing the methodology. Implementation Science, 5(1), 1-9; 9.

Lyall, C., Bruce, A., Marsden, W., Meagher, L. (2011). Identifying key success factors in the quest for interdisciplinary knowledge. Report to NERC. Retrieved from http://www. ei.udelar.edu.uy/resources/1/9/o/o/6_727fbo8f25be2a1/19006_a2492bo87bcadd4.pdf.

Lyall, C., \& Meagher, L.R. (2012). A masterclass in interdisciplinarity: Research into practice in training the next generation of interdisciplinary researchers. Futures, 44(6), 608-617.

Lyall, C., Meagher, L.R., Tait, J. (2008). A short guide to supervising interdisciplinary PhDs. Briefing Note. Edinburgh: Institute for the Study of Science Technology and Innovation. Retrieved from https://www.wiki.ed.ac.uk/display/ISSTIInterdisciplinary/ ID+Short+Notes+and+other+reference+materials.

Manathunga, C. (2007). Supervision as mentoring: The role of power and boundary crossing. Studies in Continuing Education, 29 (2), 207-221.

Manathunga, C., Lant, P., \& Mellick, G. (2006). Imagining an interdisciplinary doctoral pedagogy. Teaching in Higher Education, 11(3), 365-379.

Martin, D. (2011). Reflecting about interdisciplinary post-graduation education. Saude E Sociedade, 20(1), 57-65.

Mays, N., Roberts, E., \& Popay, J. (2001). Synthesising research evidence. Studying the Organization and Delivery of Health Services: Research Methods, 188-220.

McCallin, A., \& Nayar, S. (2012). Postgraduate research supervision: a critical review of current practice. Teaching in Higher Education, 17 (1), 63-74.

McGee, R., \& DeLong, M. J. (2007). Collaborative co-mentored dissertations spanning institutions: Influences on student development. Life Sciences Education,6 (2), 119-131.

McVicar, A., Caan, W., Hillier, D., Munn-Giddings, C., Ramon, S., \& Winter, R. (2006). A shared experience: An interdisciplinary professional doctorate in health and social care. Innovations in Education and Teaching International, 43(3), 211-222.

McWilliam, E., \& Palmer, P. (1995). Teaching tech(no)bodies: Open learning and postgraduate pedagogy. Australian Universities' Review, 38(2), 32-34.

Mitchell C. (2009a). Zen and the Art of Transdisciplinary Postgraduate Studies: Final Report for ALTC Fellowship. Prepared by the Institute for Sustainable Futures. Sydney: University of Technology,

Mitchell C. (Ed.). (2009b). Quality in Interdisciplinary and Transdisciplinary Postgraduate Research and its Supervision: Ideas for Good Practice. Prepared for ALTC Fellowship: Zen and the Art of Transdisciplinary Postgraduate Studies. Sydney: Institute for Sustainable Futures, University of Technology.

Mitchell C., \& Willetts J., 2009. Quality criteria for inter- and trans $\square$ disciplinary doctoral research outcomes. Prepared for ALTC Fellowship: Zen and the Art of Transdisciplinary Postgraduate Studies. Sydney: Institute for Sustainable Futures, University of Technology. 
Mitrany, M., \& Stokols, D. (2005). Gauging the transdisciplinary qualities and outcomes of doctoral training programs. Journal of Planning Education and Research, 24(4), 437-449.

National Science Foundation. (2011). IGERT: Integrative graduate education and research traineeship. Retrieved from http://www.igert.org/

Nightingale, P., \& Higher Education Research and Development Society of Australasia. (2005). Advising PhD candidates. Milperra, NSW: Herdsa.

Nisselle, A., \& Duncan, R. (2008). Multiple supervisors from multiple disciplines: Lessons from the past as multidisciplinary supervision becomes the way of the future. Traffic (Parkville), 1O(1), 143.

Parchoma, G., \& Keefer, J. (2012). Contested disciplinarity in international doctoral supervision. In Hodgson, V., Jones, C., de Laat, M., et al (Eds), Proceedings of the 8th International Conference on Networked Learning. 498-505.

Petersen, E. B. (2007). Negotiating academicity: Postgraduate research supervision as category boundary work. Studies in Higher Education, 32(4), 475-487.

Pfirman, S., \& Martin, P. (2010). Facilitating interdisciplinary scholars. In R. Frodeman, J. Thompson Klein \& C. Mitcham (Eds.), The Oxford Handbook of Interdisciplinarity (pp. 387). Oxford; New York: Oxford University Press.

Phillips, E., \& Pugh, D. S. (2005). How to get a PhD: A handbook for students and their supervisors (4th ed.). New York: Open University Press.

Pinar, W. (2004). What is curriculum theory? Mahwah, NJ; London: Lawrence Erlbaum.

Pohl, C., von Kerkhoff, L., Hirsch Hadorn, G., Bammer, G. (2008). Core terms in transdisciplinary research. In Hirsch Hadorn, G., Hoffman-Riem, H., Biber-Klemm, S., Grossenbacker-Mansuy, D., et al. (Eds.), Handbook of Transdisciplinary Research (pp.427-432). Dordrecht: Springer.

Pole, C. (1998). Joint supervision and the PhD: Safety net or panacea? Assessment \& Evaluation in Higher Education, 23(3), 259-271.

Rhoten, D. (2003). Final report: A multi-method analysis of the social and technical conditions for interdisciplinary collaboration. San Francisco: The Hybrid Vigor Institute.

Rhoten, D. (2004). Interdisciplinary research: Trend or transition. Social Science Research Council (SSRC), 5, 6-11.

Rhoten, D., Boix-Mansilla, V.,Chun,M., \& Klein,J.Thompson.(2006).Interdisciplinary education at liberal-arts institutions. Teagle Foundation White Paper. Retrieved from http://www.evergreen.edu/washcenter/resources/upload/2006_ssrc_whitepaper.pdf.

Rhoten, D., \& Parker, A. (2004). Risks and rewards of an interdisciplinary research path. Science, 306(5704), 2046-2046.

Robinson, N. (1997). The student-supervisor relationship. In P. Burnham (Ed.), Surviving the research process in politics (pp. 71). London; Washington DC: Pinter.

Sá, C. M. (2006). Interdisciplinary strategies at research-intensive universities. Doctoral dissertation, Pennsylvania State University. 
Sá, C. M. (2008a). 'Interdisciplinary strategies' in U.S. research universities. Higher Education, 55(5), 537-552.

Sá, C. M. (2008b). Strategic faculty hiring in two public research universities: Pursuing interdisciplinary connections. Tertiary Education and Management, 14(4), 285-301.

Sambrook, S., Stewart, J., Roberts, C. (2008). Doctoral supervision ... A view from above, below and the middle. Journal of Further and Higher Education, 32(1), 71-84.

Sampson, K. A., \& Comer, K. (2010). When the governmental tail wags the disciplinary dog: Some consequences of national funding policy on doctoral research in New Zealand. Higher Education Research \& Development, 29(3), 275-289.

Semenza, G. M. C. (2005). The graduate study for the twenty-first century: How to build an academic career in the humanities. New York: Palgrave Macmillan.

Skarakis-Doyle, E., \& Doyle, P. C. (2008). The ICF as a framework for interdisciplinary doctoral education in rehabilitation: Implications for speech-language pathology. International Journal of Speech-Language Pathology, 10(1-2), 83-91.

Smith, B. (2001). Re(framing) research degree supervision as pedagogy. In A. Bartlett, \& G. Mercer (Eds.), Postgraduate research supervision: Transforming (r)elations (p. 25). New York: Lang.

Smith, S. (1997). Combining disciplines: How to build a good enough bridge. In P. Burnham (Ed.), Surviving the research process in politics (p. 133). Washington D.C.: Pinter.

Spelt, E., Biemans, H., Tobi, H., Luning, P., \& Mulder, M. (2009). Teaching and learning in interdisciplinary higher education: A systematic review. Educational Psychology Review, 21(4), 365-378.

Stufflebeam, D. L. (2001). Interdisciplinary Ph.D. programming in evaluation. American Journal of Evaluation, 22(3), 445-55.

Sugimoto, C. R. (2010). Mentoring, collaboration, and interdisciplinarity: An evaluation of the scholarly development of information and library science doctoral students. Doctoral dissertation, University of North Carolina at Chapel Hill.

Taylor, S., Beasley, N., \& Ebrary, I. (2005). A handbook for doctoral supervisors. New York: Routledge.

Tress, B., Tress, G., \& Fry, G. (2009). Integrative research on environmental and landscape change: PhD students' motivations and challenges. Journal of Environmental Management, 9o(9), 2921-2929.

Wall, S., \& Shankar, I. (2008). Adventures in transdisciplinary learning. Studies in Higher Education, 33(5), 551-565.

Wickson, F., Carew, A. L., \& Russell, A. W. (2006). Transdisciplinary research: Characteristics, quandaries and quality. Futures, 38(9), 1046-1059.

Wisker, G. (2005). The goodsupervisor:Supervising postgraduateandundergraduate research for doctoral theses and dissertations. New York: Palgrave Macmillan. 


\section{Contact Information}

Meredith Vanstone

McMaster University

Department of Clinical Epidemiology and Biostatistics

1280 Main Street West

Hamilton, Ontario L8S4L8

meredith.vanstone@mcmaster.ca

Meredith Vanstone, PhD., is an Assistant Professor at the Centre for Health Economics and Policy Analysis, Department of Clinical Epidemiology and Biostatistics, McMaster University. She is the graduate of interdisciplinary doctoral (Health Professional Education) and baccalaureate programs (Philosophy and Health Studies) and currently teaches in an interdisciplinary doctoral program (Health Policy). Her research interests centre around social and ethical dimensions of health policy decision making, medical education, and women's health.

Kathy Hibbert, PhD., is an Associate Professor at the Faculty of Education and Acting Associate Director, Centre for Education Research and Innovation, the Schulich School of Medicine \& Dentistry, Western University, London, Canada. Her research interests involve working across disciplines and communities of professional practice to ask, how do our abilities to «read» texts and to use and understand multimedia/other technologies shape our ability to communicate and learn? Recent publications have considered this question through the lens of Aristotle's notion of phronesis; through the "place-conscious" movement in rural literacies and through the "multiliteracies approach" forwarded by New Literacies scholars.

Elizabeth Anne Kinsella, PhD., is an Associate Professor in Faculty of Health Sciences, at Western University with cross appointments in the Faculty of Education and the Department of Women's Studies and Feminist Research. Her work is broadly located in the interdisciplinary field of Health Professional Education. She is engaged in theoretical and empirical work that contributes to understanding about reflection, reflective practice, reflexivity, and dialogue as they relate to knowledge generation in the professions. Dr. Kinsella is field leader of an interdisciplinary graduate program in Health Professional Education and has published over 40 journal articles and book chapters.

Pam McKenzie, PhD., had a brief undergraduate career in physics before moving to international relations and from there to graduate degrees in history and, finally, Library and Information Science (LIS). She is Associate Professor and Associate Dean in the Faculty of Information and Media Studies at Western University. She has served on thesis committees in LIS, Health Science, Education, Media Studies, and Women's Studies. She is interested in temporal, textual, and interactional aspects of information seeking, sharing, and use in the intersections of information work and caring work, and in gendered and embodied information practices and spaces. 


\begin{abstract}
Allan Pitman, PhD., is an Associate Professor in the Faculty of Education at Western University with a background in mathematics education and comparative education. His research interests are in the temporal and sociopolitical location of the work of members of professions, and in the processes of reform in professional practice with particular reference to the work of teachers. He also studies the sociopolitical influences on the content of mathematics curricula. Some recent work has focused on the changing role of the university.

Lorelei Lingard, PhD., is a leading researcher in the study of communication and collaboration on health-care teams. She is a Professor in the Department of Medicine and the Director of the Centre for Education Research \& Innovation at the Schulich School of Medicine and Dentistry at Western University. Lorelei received her PhD in Rhetoric from Simon Fraser University in 1998. Her research program investigates the nature of communication on inter-professional health-care teams in a variety of clinical settings. Lorelei's research program is funded by CIHR, SSHRC, Health Canada, MOHLTC, the RCPSC, and other agencies.
\end{abstract}

